\title{
Impact of environmentally relevant concentration of benzophenone-3 on antioxidant enzymes, oxidative stress markers and morphology of gills in Danio rerio (Hamilton)
}

\author{
S Velanganni ${ }^{1}$, P Sivakumar ${ }^{2}$ and S Miltonprabu ${ }^{1, *}$ \\ ${ }^{1}$ Department of Zoology, Annamalai University, Annamalai Nagar-608002, India. \\ 2 Department of Zoology, APSA College, Thiruppattur- 630211 Tamil Nadu, India.
}

GSC Biological and Pharmaceutical Sciences, 2021, 14(03), 189-196

Publication history: Received on 08 January 2021; revised on 10 March 2021; accepted on 12 March 2021

Article DOI: https://doi.org/10.30574/gscbps.2021.14.3.0043

\begin{abstract}
The current investigation intended to evaluate the effect of Benzophenone-3 (BP-3) at the environmentally relevant concentration $(44 \mu \mathrm{g} / \mathrm{L})$ in the gills of Danio rerio through evaluating oxidative stress markers and histopathological analysis. The adult Zebra fish was exposed to BP-3 at environmentally relevant concentration for 45 days. During the experimental period of 15,30 and 45 days, lipid peroxidation markers like thiobarbituric acid reactive substances (TBARS) and Hydrogen peroxide $\left(\mathrm{H}_{2} \mathrm{O}_{2}\right)$, antioxidant enzymes such as superoxide dismutase (SOD), catalase (CAT), Glutathione peroxidase (GPx) and non-enzymatic glutathione (GSH) in the gill and histology of gill were analyzed. The activity of TBARS and H2O2 was found to be significantly higher meanwhile the activities of antioxidant enzymes viz., SOD, CAT, GPx and Glutathione (GSH) level were found to be significantly reduced in the gill of BP-3 treated fish for 30 and 45 days. Additionally, the morphology of gill also showed several abnormal changes in their morphology when compared to control. BP-3 exposure for 15 days elicited only mild alterations in the biochemical and histopathological variables when compared to 30 and 45 days exposure. Further, the values were also non-significant when compared to the control fish. These results demonstrated that the treatment of BP-3 at environmentally relevant concentration could prominently alter the respiratory physiology and metabolism of the gills of Danio rerio.
\end{abstract}

Keywords: Benzophenone-3; Danio rerio; lipid peroxidation; oxidative stress; antioxidants

\section{Introduction}

Benzophenone-3 (BP-3) is one of the most commonly used organic UV-filter compounds [1,2]. Widespread use of BP-3 has led to the release of this compound into aquatic environments worldwide [2]. BP-3 is a broad-spectrum UV absorber that can effectively absorb UV light ranging from 290-440 nm, but does not absorb any visible light. BP-3 can get absorbed through both the mouth as well as skin of humans as it's lipophilicity, light stability, and bioaccumulation [3]. The widespread use of BP-3 has resulted in its release into the water environment, and hence its potential impact on the aquatic ecosystem is of concern [2]. In the aquatic environment, BP-3 ranges from ng to $\mu \mathrm{g} / \mathrm{L}$. The highest concentrations detected are $44 \mu \mathrm{g} / \mathrm{L}$ in the river, $34.3 \mu \mathrm{g} / \mathrm{L}$ in seawater, $10.4 \mu \mathrm{g} / \mathrm{L}$ in wastewater influent, $4.5 \mu \mathrm{g} / \mathrm{L}$ in the swimming pool, $0.45 \mu \mathrm{g} / \mathrm{L}$ in tap water, $0.2 \mu \mathrm{g} / \mathrm{L}$ in the lake, and $0.034 \mu \mathrm{g} / \mathrm{L}$ in groundwater $[2,4]$.

The gill is the site of gas exchange, ionic regulation, acid-base balance, and nitrogenous waste excretion by fishes. The last three processes are controlled by passive and active transport of various solutes across the epithelium. Various environmental pollutants (e.g., heavy metals, acid rain, and organic xenobiotics) have been found to affect the gill's morphology [5]. Some previous reports displayed that the BP-3 toxicity such as declined the growth of experimental

\footnotetext{
${ }^{*}$ Corresponding author: S Miltonprabu

Department of Zoology, Annamalai University, Annamalai Nagar-608002.

Copyright (C) 2021 Author(s) retain the copyright of this article. This article is published under the terms of the Creative Commons Attribution Liscense 4.0.
} 
animals [6], endocrine disruption [7], interferes with functions of human sperm cells in vitro [8], induce maternal and developmental toxicity [9] and alter the mammary gland morphology and function [10]. In our previous report, we stated that at the environmentally relevant concentration of BP-3 (44 $\mu \mathrm{g} / \mathrm{L}$ in the river) can alter the activity of antioxidant enzymes, the content of protein and glycogen and morphology of liver in Zebra fish [11]. Therefore, the present study designed to evaluate the effect of BP-3 at the environmentally relevant concentration of (44 $\mu \mathrm{g} / \mathrm{L}) \mathrm{on}$ antioxidants, oxidative stress markers and morphology of gill of Danio rerio.

\section{Material and methods}

\subsection{Chemicals}

Benzophenone-3 (CAS Number: 2421-28-5, 98\% purity) was procured from Sigma Aldrich, USA. All other chemicals and reagents used were all of the analytical grade and obtained from the Merck, Himedia, Mumbai, India.

\subsection{Experimental fish}

The adult Danio rerio (wild-type, AB strain) of both genders ( $0.5 \pm 0.3 \mathrm{~g} ; 3.1 \pm 0.4 \mathrm{~cm}$ length) were got from the Red hills fish farm, Chennai, Tamilnadu, India. Fishes were acclimatized to laboratory conditions in continuously aerated dechlorinated tap water and maintained under a photoperiod of 12-h/12-h light-dark cycle. During the acclimatization period, fish were fed twice a day with commercial pellets, and the residues and metabolic wastes were removed daily.

\subsection{Stock solution preparation}

BP-3 (purity N 98\%, Sigma) stock solution (1000 mg/L) was prepared in 100\% dimethyl sulfoxide (DMSO) and then stored at $-20^{\circ} \mathrm{C}$. The working solutions were later prepared by diluting the stock solution immediately before the experiments. The standard solution was added to the experimental vessel with test fish to attain an environmentally relevant concentration of BP-3 $(44 \mu \mathrm{g} / \mathrm{L})$.

\subsection{Experimental design}

The adult experimental fishes were exposed to BP-3 at the environmentally relevant concentration ( $44 \mu \mathrm{g} / \mathrm{L}$ ) for 45 days duration. A group of 100 healthy fishes of similar size were exposed to the BP-3, at environmentally relevant concentration, along with a control group of similar fishes also maintained at the same conditions. Three replicates were maintained for each concentration and control groups. The medium and the test solutions were renewed at the end of $24 \mathrm{~h}$ until 45 days. Feeding was stopped at different intervals (15, 30 and 45 days) and fish were starved $24 \mathrm{~h}$ before dissection with mild anesthesia.

\subsection{Sample preparation}

At the end of 15, 30 and 45 days of exposure periods, fish $(n=25)$ were collected from the control and BP-3 exposed groups, washed with distilled water and then blotted dry on a tissue paper. The gill tissues were detached from BP-3 treated and control groups. In a Teflon homogenizer, $100 \mathrm{mg}$ of gill tissue (pooled samples) and $1.0 \mathrm{~mL}$ of $0.1 \mathrm{M}$ Tris$\mathrm{HCl}$ buffer (PH 7.5) were added and then squeezed. The mixture was centrifuged at $10000 \mathrm{rpm}$ for $15 \mathrm{~min}$ at $4^{\circ} \mathrm{C}$, and supernatant was separated and later used for the oxidative stress analysis.

\subsection{Lipid peroxidation and antioxidant analysis}

The activity of TBARS and $\mathrm{H}_{2} \mathrm{O}_{2}$ in gill was estimated by following the method of Fraga et al. [12] and Jiang et al. [13], respectively. The activity of SOD was determined by the method of Marklund and Marklund [14]. The activity of CAT was determined according to the procedure of Aebi [15]. The activity of GPx was determined by the method of Rotruck et al. [16]. The non-enzymatic antioxidant GSH in gill tissue was estimated by the method of Ellman [17].

\subsection{Histopathology analysis}

The harvested gill tissue samples were fixed for $48 \mathrm{~h}$ in $10 \%$ formalin-saline and then dehydrated by passing successfully through different mixture of ethyl alcohol, water, cleaned in xylene and embedded in paraffin. Sections of the tissues (5-6 $\mu \mathrm{m}$ thick) were prepared by using a rotary microtome and stained with haematoxylin and eosin (H\& E) dye, which was later mounted in a neutral deparaffined xylene medium for microscopical observations. 


\subsection{Statistics}

All the results were presented as mean \pm SD of ten fish $(n=10)$ in each group. The $p$ value of $<0.05$ was considered as statistically significant by one-way analysis of variance (ANOVA) followed by Duncan's Multiple Range test (IBM SPSS Statistics for Windows, version 15).

\section{Results and discussion}

\subsection{Effect of BP-3 on lipid peroxidation markers}

Figure $1 \& 2$ represents the amount of TBARS and $\mathrm{H}_{2} \mathrm{O}_{2}$ in the gills of control and BP-3 at the environmentally relevant concentration ( $44 \mu \mathrm{g} / \mathrm{L}$ ) exposed Zebra fish. The amount of TBARS and $\mathrm{H}_{2} \mathrm{O}_{2}$ were increased significantly in the gills of BP-3 exposed Zebra fish as compared to the normal fish. A significant $(\mathrm{p}<0.05)$ progressively increased the production of TBARS and $\mathrm{H}_{2} \mathrm{O}_{2}$ in the gill was observed from 30, and 45 days of BP-3 exposure, whereas it was not significant at 15 days.

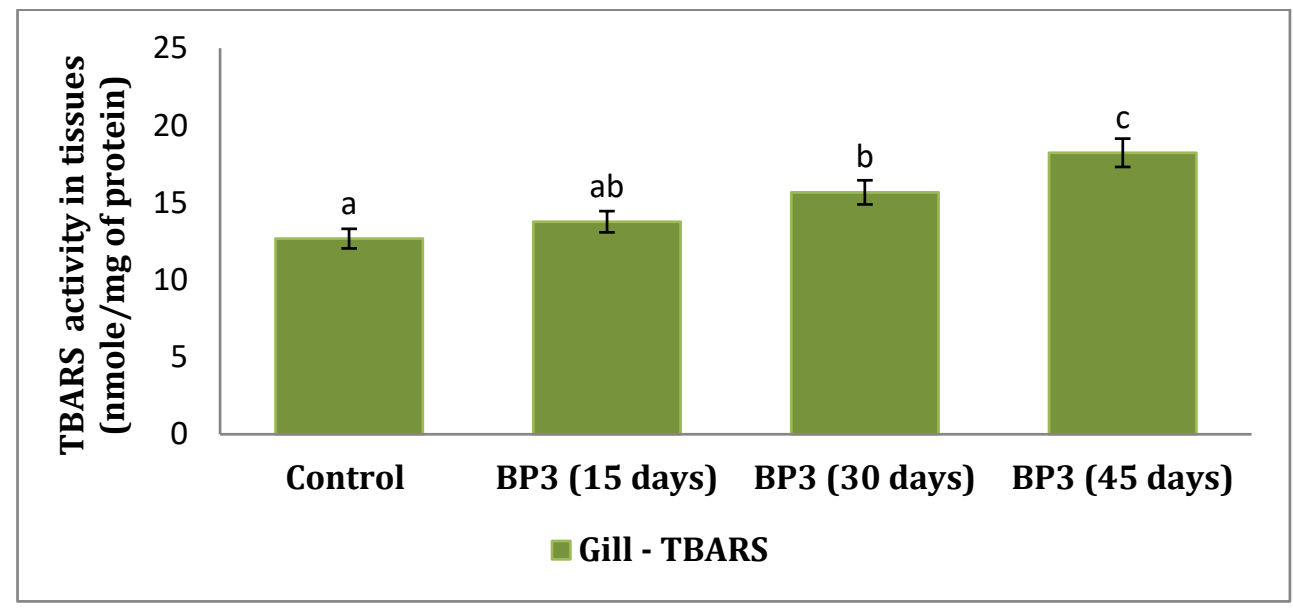

Figure 1 Effect of UV filter BP-3 on TBARS in the gills of Zebra fish

All the data were expressed as the mean \pm S.D. for 10 fish. The results with different superscripts (a, b \& c) for the gills at different exposure periods (15, 30 and 45 days) are significantly different at $\mathrm{p}<0.05$.

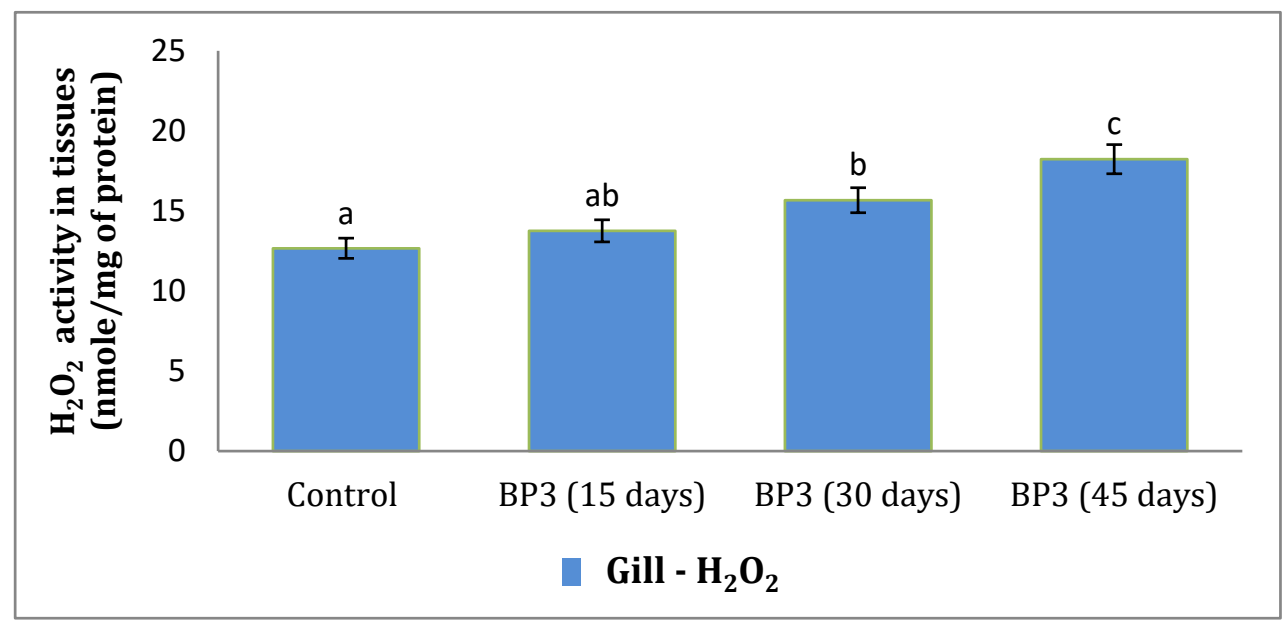

Figure 2 Effect of UV filter BP-3 on hydrogen peroxide in the gills of Zebra fish

All the data were expressed as the mean \pm S.D. for 10 fish. The results with different superscripts (a, b \& c) for the gills at different exposure periods (15, 30 and 45 days) are significantly different at $p<0.05$. 


\subsection{Effect of BP-3 on enzymatic antioxidant}

The antioxidant activity of SOD, CAT and GPx in the gills of control and BP-3 exposed fish are represented in Table 1. The antioxidant enzymes of SOD, CAT and GPx activities were notably declined at an environmentally relevant concentration of BP-3 exposed Zebra fish as compared with the control group. A significant decline in the activity of SOD, CAT and GPx were found to at 30 and 45 days BP-3 treated fish gills when compared to the control. Meanwhile, the activities were slightly increased from 15 days exposed fish then control.

Table 1 Effect of BP-3 on enzymatic antioxidant in the gills of Zebra fish

\begin{tabular}{|l|l|l|l|l|}
\hline Experimental periods & Control & BP-3 (15 days) & BP-3 (30 days) & BP-3 (30 days) \\
\hline SOD & $8.2 \pm 0.62^{\mathrm{a}}$ & $8.5 \pm 0.35^{\mathrm{a}}$ & $7.2 \pm 0.55^{\mathrm{b}}$ & $6.3 \pm 0.22^{\mathrm{c}}$ \\
\hline CAT & $9.87 \pm 0.75^{\mathrm{a}}$ & $10.05 \pm 0.64^{\mathrm{a}}$ & $7.48 \pm 0.43^{\mathrm{b}}$ & $6.36 \pm 0.54^{\mathrm{c}}$ \\
\hline GPx & $11.88 \pm 0.91^{\mathrm{a}}$ & $12.19 \pm 0.78^{\mathrm{a}}$ & $9.23 \pm 0.64^{\mathrm{b}}$ & $8.94 \pm 0.39^{\mathrm{c}}$ \\
\hline
\end{tabular}

SOD in gill was expressed as 50\% inhibition of nitroblue tetrazolium reduced in 1 minute/mg protein; CAT in gill was expressed as $\mu$ moles of $\mathrm{H}_{2} \mathrm{O}_{2}$ consumed/minute/mg protein; GPx in gill was expressed as $\mu \mathrm{g}$ of GSH consumed $/$ minute/mg protein. All the data were expressed as the mean \pm S.D. for 10 fish. The results with different superscripts $(\mathrm{a}, \mathrm{b}, \mathrm{c})$ for the gills at different exposure periods $(15,30$ and 45 days) are significantly different at $\mathrm{p}<0.05$.

\subsection{Effect of BP-3 on non-enzymatic antioxidant}

Figure 3 represents the level of GSH in the gills of control, and BP-3 exposed Zebra fish. The activity of GSH was slightly increased from 15 days exposure of environmentally relevant concentration of BP-3 when compared to the control fish tissues. Whereas, the level of GSH was significantly declined from 30 and 45 days exposure of BP-3 fish tissues when compared to the control.

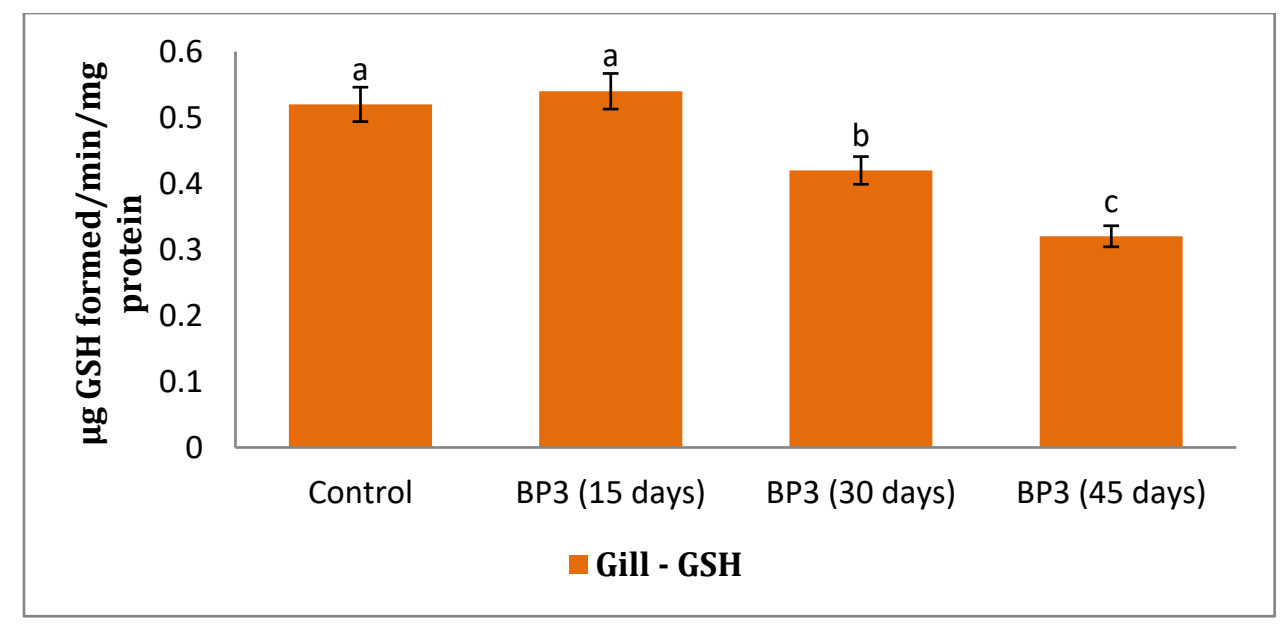

Figure 3 Effect of UV filter BP-3 on non-enzymatic antioxidant GSH in the gills of Zebra fish

All the data were expressed as the mean \pm S.D. for 10 fish. The results with different superscripts $(a, b$ \& $c)$ for the gills at different exposure periods (15, 30 and 45 days) are significantly different at $p<0.05$.

\subsection{Gill histopathology}

Figure 4 shows the gill histology of environmentally relevant concentration of BP-3 treated and control D. rerio. The histomorphology of the control group displayed a normal anatomical structures found in a healthy fish, i.e., the secondary lamellae were coated with simple squamous epithelium. Pillar cells were observed supporting the capillaries. An interlamellar mass was observed between the secondary lamellae with the presence of mitochondria-rich cells (MRC) (also called chloride cells) only in this region. The MRCs were identified as large epithelial cells with strong eosinophilic cytoplasm (Figure 4A ). The gills from the 15 days exposure group (BP-3 -15 days) had apparently thinner primary lamella, with few cells in the interlamellar regions, mainly the MRCs (Figure 4B). Whereas, the fish from BP-3- 
30 days and BP-3-45 days treated groups respectively (Figure 4C \& 4D), presented the highest amount of alterations in the gills, which was observed with disorganization of lamellar structure, epithelial lifting, and MRC disorganization in the secondary lamellae.

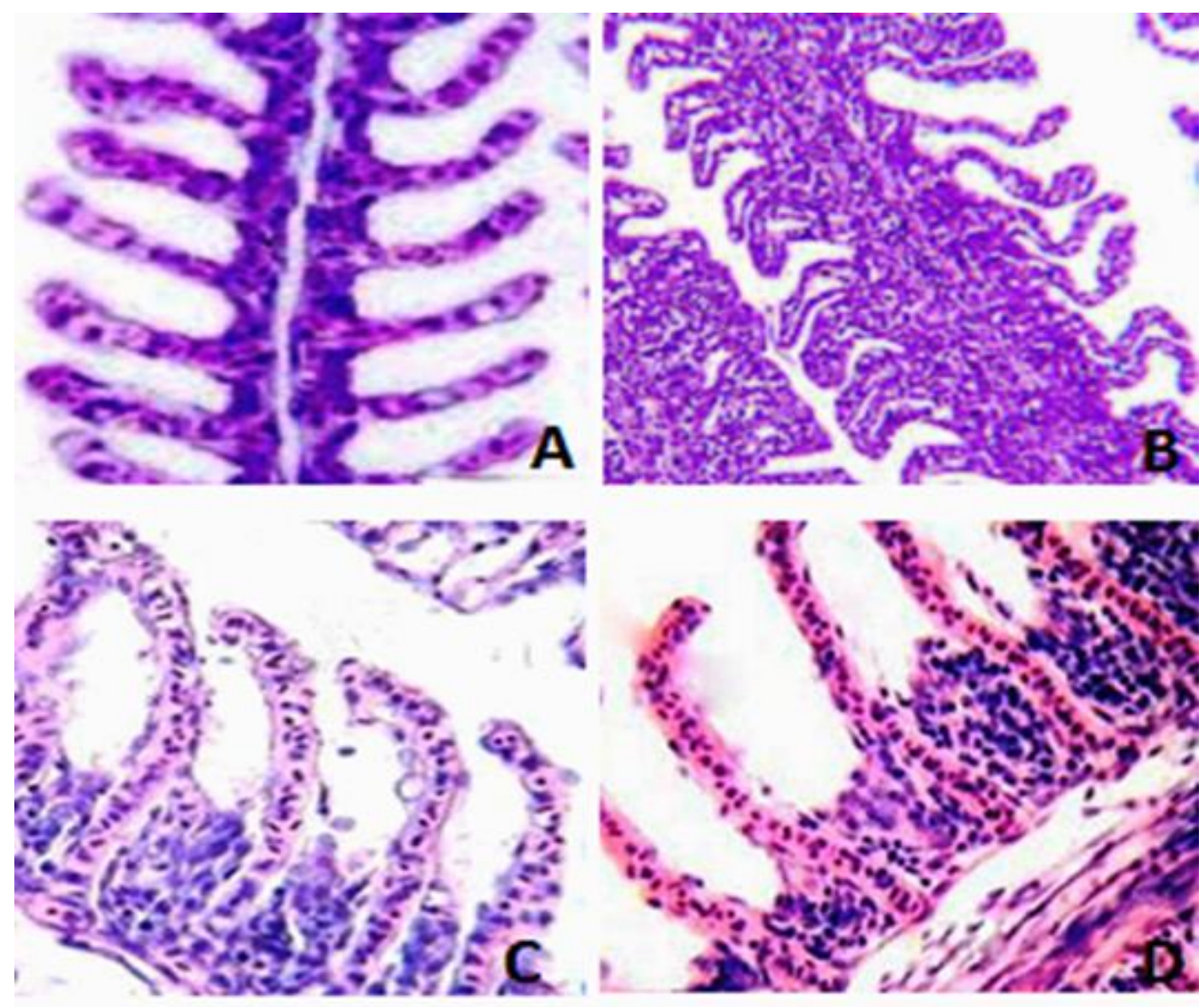

Figure 4 Histological sections of gill of D. rerio from control group (A), and from the groups treated with benzophenone3 for 15 days (B), 30 days (C) and 45 days (D) stained with Hematoxylin and Eosin (HE), x100.

D. rerio possesses four pairs of gills, each bearing two rows of primary gill lamellae (PL) (gill filaments) which in turn bear series of secondary lamellae (SL) (respiratory lamellae) on both sides arranged alternatively. The lining of the SL on each side consists of single layered epithelium which rests on a basement membrane covering serially arranged row of pillar cells. These pillar cells alternate with blood channels to form the vascular component of the SL. Mucous cells (MCs) (Fig. 4A) are mostly observed in between the two SL and also at the distal tip of PL. On exposure to environmentally relevant sublethal concentration of BP-3 to the gills showed extensive damages in their lamellar configuration even though the gills continue to regenerate repeatedly after every wear and tear, especially during the initial stages. The gill showed fusion of SL with the neighboring gill filament and form undifferentiated mass of cells after $15 \mathrm{~d}$ of exposure (Fig.4B). The blood vessels running through PL show congestion of blood material and appeared red due to engorgement of RBCs. After $30 \mathrm{~d}$ of exposure the respiratory epithelium of the SL frequently became lifted from the pillar cell system and complete fusion of SL occurred (Fig.4C) and the PL became highly vacuolated. Large scale of wear and tear in the PL as well as SL took place after $45 \mathrm{~d}$ of exposure in the form of extensive fusion and vacuolization (Fig. 4D) which induced severe hemorrhage.

\section{Discussion}

In the current study, we assessed the effect of BP-3 at the environmentally relevant concentration on the gills of Danio rerio. Our results displayed that BP-3 exposure at the environmentally relevant concentration for 45 days, notably altered the antioxidant enzymes' activity, and altered the morphology of gills in Zebra fish. 
Lipid peroxidation level (LPO) is a popular biomarker for assessing environmental pollution [18]. It is particularly important for aquatic animals since they usually contain a greater amount of polyunsaturated fatty acids than others, which has been reported to be a major contributor to the loss of cell function [19]. It is the initial step of cellular membrane damage caused by pro-oxidants, xenobiotics and their metabolites [19,20]. It is considered as an indicator of oxidative damage of cellular components and is analysed by estimating TBARS and $\mathrm{H}_{2} \mathrm{O}_{2}$. In the present study, the activity of TBARS and $\mathrm{H}_{2} \mathrm{O}_{2}$ was found to be higher at an environmentally relevant concentration of BP-3 exposed fish gill then control at 30 and 45 days interval. These findings indicate that the accumulation of BP-3 in tissues may provoke ROS production, and in turn, affect the CAT activity, which catalyses and neutralizes the $\mathrm{H}_{2} \mathrm{O}_{2} \mathrm{H}_{2} \mathrm{O}_{2}$ derived from oxidative stress. These findings were supported by Huang et al. [21] who stated that UV filters BP-3 increased the LPO marker malondialdehyde in Zebra fish liver, which significantly changed during the whole BP-3 exposure period.

Oxidative stress occurs if the activity of the antioxidant defense systems like SOD, CAT and GPx (glutathione peroxidase) were altered by the environmental pollutants mediated production of reactive oxygen species (ROS) [22]. Antioxidants system prevent the uncontrolled formation of ROS or inhibit their reactions with biological structures. Hydrophilic scavengers are found in cytosolic, mitochondrial, and nuclear compartments [23]. The three major antioxidant enzymes are SOD, CAT, and GPx. SOD can catalyse the dismutation of the superoxide radical to $\mathrm{H}_{2} \mathrm{O}_{2}$ and molecular oxygen. Then it can be converted to $\mathrm{H}_{2} \mathrm{O}$ by CAT and GPx [24]. These enzyme activities were found to be declined in the gills of fish when exposed to BP-3 at environmental concentration, which may be due to the inhibition of these enzymes by increased cellular $\mathrm{H}_{2} \mathrm{O}_{2}$ levels. This findings supported by Huang et al. [21], reported that the activity of SOD and CAT in the liver of Zebra fish was inhibited by UV filters BP-4, PABA and PBSA exposure.

Reduced glutathione (GSH) is the major non-protein thiol and plays a pivotal role in cell viability, protecting cells against lipid peroxidation either alone or in conjugation with other proteins [25]. Earlier, Camara et al. [26] and Ahn et al. [27] have reported that the exposure to organic pollutants may result in either increase or decrease of GSH levels in the test organisms. Our results showed that the content of GSH was found to be low in the gills of Zebra fish that were exposed to an environmentally relevant concentration of BP-3. This reduction in the GSH level may be due to the accumulation of BP-3 that led to the increased utilization or depletion (oxidation to GSSG) of GSH for the detoxification of BP-3 and increased production ROS in the tissues due to BP-3 accumulation. The present finding was supported by Gao et al. [28], who reported that the content of GSH was declined in Tetrahymena thermophila exposed to BP-3.

The most contact between fish and polluted water occurred through the gills. Gill tissue damage and changes in the immune response against the toxin and pollutants was studied by Reddy and Rawat [29]. The gills separate the blood from the water only by a few micrometres which not only facilitate the exchange of gases but also allows the gill tissue to be exposed to variations in the environment. Consequently, the existence of toxic materials in the environment causes alterations in the vital functions carried out by the gills and changes in the morphologic structure of the gills [30]. The BP-3, at environmentally relevant concentration exposure, on D. rerio was characterized by a less prominent primary lamellar thickness, interlamellar area reduction, and significant increase in MRCs number when compared with the control group. These findings suggested that BP-3 intake is mostly occurring through the gills of fishes. The lamellar epithelial lining the gill reacts with dissolved BP-3, creating osmoregulatory tissue imbalance. The cumulative result would be the reduced flow of oxygen-enriched water to lamellar tissues and ultimately affect the reduction of its physical activity and performance [31].

\section{Conclusion}

Our findings disclosed that at an environmentally relevant concentration of BP-3 (44 $\mu \mathrm{g} / \mathrm{L})$ altered the activity or levels of lipid peroxidation markers (TBARS, $\mathrm{H}_{2} \mathrm{O}_{2}$ ), enzymatic antioxidants (SOD, CAT and GPx), non-enzymatic antioxidant GSH as well as the gill morphology of Zebra fish. Thus, from the above results, it is evident that, the long-term exposure of BP-3, even at environmentally relevant concentration, may impose a severe threat on the normal development of economically important fishes and in turn may affect the economy of the aquaculture industries as well as the health status of the consumers.

\section{Compliance with ethical standards}

\section{Acknowledgments}

The Authors are grateful to Dr. G. Jagadeesan, Professor and Head, Department of Zoology, Annamalai University, Faculty of Science, for guidance and use of their laboratory equipment. 


\section{Disclosure of conflict of interest}

The authors declare no conflict of interest.

\section{References}

[1] Fent K, Kunz PY, Gomez E. UV filters in the aquatic environment induce hormonal effects and affect fertility and reproduction in fish. Chimia (Aarau). 2008; 62: 368-375.

[2] Kim S, Choi K. Occurrences, toxicities, and ecological risks of benzophenone-3, a common component of organic sunscreen products: A mini-review. Environment international. 2014; 70: 143-157.

[3] Du Y, Wang WP, Fahmi A, Xu R, Zhang Y, Sun L. Acute Toxicity and Ecological Risk Assessment of Benzophenone3 (BP-3) and Benzophenone-4 (BP-4) in Ultraviolet (UV)-Filters. International Journal of Environmental Research and Public Health. 2017; 14: 1414.

[4] Ramos S, Homem V, Alves A, Santos L. Advances in analytical methods and occurrence of organic UV-filters in the environment- a review. Sci. Total Environ. 2015; 526: 278-311.

[5] Evans DH. The Fish Gill: Site of Action and Model for Toxic Effects of Environmental Pollutants. Environmental Health Perspectives. 1987; 71: 47-58.

[6] National Toxicology Program. NTP Technical Report on Toxicity Studies of 2-Hydroxy-4-methoxybenzophenone 1992; (CAS Number: 131-57-7) Administered topically and in Dosed Feed to F344/N Rats and B6C3F1 Mice. Research Triangle Park, NC: National Toxicology Program, National Institute of Environmental Health Sciences, U.S. Department of Health and Human Services.

[7] Karin L, Kinnberg, Gitte I, Petersen MA, Mita M. Endocrine disrupting effect of the ultraviolet filter benzophenone3 in Zebra fish, Danio rerio. Environmental toxicology. 2015; 34(12): 2833-2840.

[8] Rehfeld A, Dissing S, Skakkebæk NE. Chemical UV Filters Mimic the Effect of Progesterone on Ca2+ Signaling in Human Sperm Cells. Endocrinology. 2016; 157(11): 4297-4308.

[9] Danish Environmental Protection Agency. "Survey and Health Assessment of UV Filters: Survey of Chemical Substances in Consumer Products No. 142, 2015." 2015.

[10] Charlotte D, La Plante RB, Karen AD, Joseph J, Laura NV. Oxybenzone Alters Mammary Gland Morphology in Mice Exposed During Pregnancy and Lactation. J Endocr Soc. 2018; 1; 2(8): 903-921.

[11] Velanganni S, Miltonprabu S. Effect of benzophenone-3 at the environmentally relevant concentration on the liver of Zebra fish (Danio rerio (Hamilton). International Journal of Ecology and Environmental Sciences. 2020; 2(4): 640-646.

[12] Fraga CG, Leibouitz BE, Toppel AL. Lipid peroxidation measured as TBARS in tissue slices: characterization and comparison with homogenates and microsomes. J Free Rad Biol Med. 1988; 4: 155-161.

[13] Jiang ZY, Hunt JV, Wolff SP. Ferrous ion oxidation in the presence of xylenol orange for detection of lipid hydroperoxide in low density lipoprotein. Anal Biochem. 1992; 202(2): 384-389.

[14] Marklund S, Marklund G. Involvement of the superoxide anion radical in the autoxidation of pyrogallol and a convenient assay for superoxide dismutase. Eur J Biochem. 1974; 47: 469-474.

[15] Aebi H. Catalase in vitro. Methods in enzymology. 1984; 105: 121-126.

[16] Rotruck JT, Pope AL, Ganther HE. Selenium biochemical role as a component of glutathione peroxidase purification assay. Science. 1973: 179: 588-590.

[17] Ellman GL. Tissue sulfhydryl groups. Arch Biochem Biophys.1959; 82: 70-77.

[18] Islas-Flores H, Gómez-Oliván LM, Galar-Martínez M, García-Medina S, Neri-Cruz N, Dublán-García O. Effect of ibuprofen exposure on blood, gill, liver, and brain on common carp (Cyprinus carpio) using oxidative stress Biomarkers. Environmental Science and Pollution Research. 2014.

[19] Di Giulio RT, Hinton DE. The Toxicology of Fishes. Florida, USA: CRC Press. 2008; 273-324.

[20] Nwani CD, Somdare PO, Ogueji EO, Nwani JC, Ukonze JA, Nwadinigwe AO. Genotoxicity assessment and oxidative stress responses in freshwater African catfish Clarias gariepinus exposed to fenthion formulations, Drug and Chemical Toxicology. 2017; 40(3): 273-280. 
[21] Huang X, Yuanyuan LT, Shi J, Zhang X. Evaluation of the Oxidative Stress Status in Zebra fish (Danio rerio) Liver Induced by Three Typical Organic UV Filters (BP-4, PABA and PBSA) . Int. J. Environ. Res. Public Health. 2020; 17: 651.

[22] Serdar 0. The effect of dimethoate pesticide on some biochemical biomarkers in Gammarus pulex. Environ Sci Pollut Res. 2019; 26: 21905-21914.

[23] Chaudiere J, Ferrari-Iliou R. Intracellular antioxidants: from chemical to biochemical mechanisms. Food Chem Toxicol. 1999; 37(9-10): 949-62.

[24] Hayyan M, Hashim MA, Al Nashef IM. Superoxide Ion: Generation and Chemical Implications. Chem. Rev. 2016; 116:3029-3085.

[25] Anjum S, Rahman S, Kaur M, Ahmad F, Rashid H, Ahmad RA, Raisuddin S. Melatonin ameliorates bisphenol Ainduced biochemical toxicity in testicular mitochondria of mouse. Food Chem Toxicol. 2015; 49(11): 2849-2854.

[26] Camara AY, Wan Y, Yu Y, Wang Q, Li H. Effect of endogenous selenium on arsenic uptake and antioxidative enzymes in as-exposed rice seedlings. Int. J. Environ. Res. Public Health. 2019; 16: 3350.

[27] Ahn T, Park H, Kim J. Effects of antioxidant enzymes and bioaccumulation in eels (Anguilla japonica) by acute exposure of waterborne cadmium. Fish Aquatic Sci. 2020; 23: 23.

[28] Gao L, Yuan T, Zhou C, Cheng P, Bai Q, Ao J, Zhang H. Effects of Four Commonly Used UV Filters on the Growth, Cell Viability and Oxidative Stress Responses of the Tetrahymena thermophila. Chemosphere. 2013; 93(10): 2507-2513.

[29] Reddy PB, Rawat SS. Assessment of aquatic pollution using histopathology in fish as a protocol. Int. Res. J. Environ. Sci. 2013; 2: 79-82.

[30] Faheem M, Jahan N, Lone KP. Histopathological effects of bisphenol-A on liver, kidneys, and gills of Indiana major carps Catla catla (Hamilton, 1822). J. Anim. Plant Sci. 2016; 26: 514-522.

[31] Abalaka SE, Enem SI, Idoko IS, et al. Heavy Metals Bioaccumulation and Health Risks with Associated Histopathological Changes in Clarias gariepinus from the Kado Fish Market, Abuja, Nigeria. J Health Pollut. 2020; 10(26): 200602. 